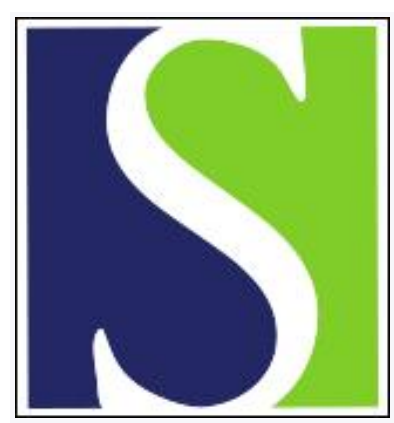

Scand J Work Environ Health 1984;10(3):203-205

https://doi.org/10.5271/sjweh.2344

Issue date: Jun 1984

Prevalence of epicondylitis and tenosynovitis among meatcutters.

by Roto P, Kivi P

This article in PubMed: www.ncbi.nlm.nih.gov/pubmed/6474113

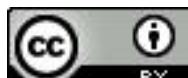




\title{
Prevalence of epicondylitis and tenosynovitis among meatcutters
}

\author{
by Pekka Roto, MD, Pertti Kivi, MD1
}

\begin{abstract}
ROTO P, KIVI P. Prevalence of epicondylitis and tenosynovitis among meatcutters. Scand $J$ Work Environ Health 10 (1984) 203-205. The prevalence of epicondylitis and tenosynovitis was assessed among 90 meatcutters and 77 referents (construction foremen). All the participants filled out a selfadministered questionnaire about subjective symptoms of the upper extremities. The questionnaire was part of the Nordic standardized questionnaire for rheumatic symptoms. The subjects were examined by the authors, who did not have prior knowledge of the subjects' occupations. The prevalence of epicondylitis and tenosynovitis among the meatcutters was 8.9 and $4.5 \%$, respectively. One referent had epicondylitis, and none suffered from tenosynovitis. The results indicate that the meatcutters had a higher risk for epicondylitis in comparison with the referents. The risk increased with age and number of exposure years.
\end{abstract}

Key terms: slaughterhouse workers, meat-processing workers.

The character of meatcutting has not changed as much as that of other types of work as the result of automatization. The major such modification to occur in this occupation has been the shifting of the physical load from general physical strain to local muscle work. The lifting and moving of slaughtered animals have been mechanized, but the cutting and separation procedures have remained physical work that loads the upper extremities and shoulders.

In Finland the daily amount of meat handled by one cutter has doubled during the last 10 years because of the demand for efficiency and because of the payroll system used by the meat industry in this country. The increasing local physical work load on the upper extremities of meatcutters, together with our observation that meatcutters often complain of upper-extremity and shoulder symptoms, was the impetus for the present study. In addition there were no other studies available concerning the prevalence of epicondylitis and tenosynovitis among meatcutters. Even the occurrence of these diseases in a normal population is poorly known (6). The relatively short duration of symptoms and the lack of epidemiologic diagnostic criteria have limited the possibilities for research on these diseases (12).

The purpose of the present study was to determine the prevalence of epicondylitis and tenosynovitis among meatcutters and to evaluate a possible association between meatcutting and epicondylitis and tenosynovitis.

\footnotetext{
1 Tampere Regional Institute of Occupational Health, SF-33101 Tampere, Finland.
}

Reprint requests to: Dr P Roto, Tampere Regional Institute of Occupational Health, PO Box 486, SF-33101 Tampere, Finland.

\section{Subjects and methods}

The study population of 90 meatcutters, all men, was selected from 250 workers examined in a project aimed at revealing the prevalence of epicondylitis and tenosynovitis among workers of meat-processing enterprises in and around the city of Tampere. Two of the companies had more than 200 workers, two about 100 workers, and the rest employed less than 50. There were two slaughterhouses, and the rest were firms producing different types of processed meats, eg, frankfurters, bologna, and other types of sausages. All the meatcutters employed by the companies took part in the study. They had all worked more than one year in the food industry, and none of them currently had tasks other than meatcutting in their daily work.

The reference group was formed of 77 foremen from the construction industry. The foremen were selected as the referents because they had not been exposed to repetitive movements of the upper extremities in their work.

We chose the following commonly used signs for the determination of epicondylitis (12): local tenderness, pain during resisted extension/flexion of the wrist and fingers, and decreased hand grip power in comparison to that of the opposite hand. The diagnosis of tenosynovitis required the following symptoms: local pain during movement, swelling, and weakness of finger movements.

All the participants filled out a self-administered questionnaire about subjective symptoms of the upper extremities and located the painful areas on a picture representing the upper part of the body. The questionnaire was a part of the Nordic standardized questionnaire for rheumatic symptoms (1). The subjects came to the physical examination with the ques- 
tionnaire already filled out. They were then checked by one of us, neither of whom had any prior knowledge of the subjects' occupation because, at the time of the examination, the subjects were part of the larger group of 250 meat-processing workers. Every other worker was assigned to one of the authors in turn. All of the workers in whom objective symptoms were found were referred for serologic laboratory tests for rheumatic arthritis (the latex test and sedimentation rate). The physical examination was performed about $1-2 \mathrm{~h}$ after the beginning of the workday.

Seventy-two of the 77 referents participated in the physical examination. The health records of the five nonparticipating referents were checked. They did not participate in the examination because they were traveling on business. There was no indication that they would have had either epicondylitis or tenosynovitis.

The Mantel-Haenszel chi square (7) for several $2-x-2$ frequency tables, stratified by confounder (in this study: age), and the associated risk ratio estimate (7) were calculated. Test-based confidence limits for the risk ratio were obtained through the application of the method introduced by Miettinen (8).

\section{Results}

Objective symptoms. Eight meatcutters $(8.9 \%)$ met the criteria for epicondylitis, and four $(4.5 \%)$ were diagnosed as having tenosynovitis (table 1 ). There was one case of epicondylitis and no cases of tenosynovitis among the referents. The cases of epicondylitis occurred in the older age groups, whereas the few cases of tenosynovitis occurred in younger workers. The one referent with epicondylitis was 58 years old. Three of the meatcutters were referred directly from the examination to therapy and sick leave.

The risk estimate for epicondylitis among the meatcutters was $6.4\left(\chi_{1}^{2}=3.81, \mathrm{p}=0.05 ; 95 \%\right.$ confidence interval $0.99-40.9$ ).

Table 1. Occurrence of epicondylitis among 90 Finnish meatcutters and 77 referents.

\begin{tabular}{lcc}
\hline $\begin{array}{l}\text { Age group } \\
\text { (years) }\end{array}$ & $\begin{array}{c}\text { Number } \\
\text { of subjects }\end{array}$ & \multicolumn{2}{c}{$\begin{array}{c}\text { Occurrence of } \\
\text { epicondylitis }\end{array}$} \\
\cline { 2 - 3 } & $\mathrm{N}$ & $\%$ \\
\hline
\end{tabular}

Meatcutters (mean age 39.2; SD 11.4)

$\begin{array}{rrrr}\leq 30 & 24 & - & - \\ 31-40 & 31 & 2 & 6 \\ 41-50 & 19 & 2 & 11 \\ 51-65 & 16 & 4 & 25 \\ \text { Total } & 90 & 8 & 1\end{array}$

Referents (mean age 38.4; SD 9.2)

\begin{tabular}{lrrl}
$<30$ & 12 & - & - \\
$31-40$ & 34 & - & - \\
$41-50$ & 18 & - & - \\
$51-65$ & 8 & 1 & - \\
Total & 72 & 1 & - \\
\hline
\end{tabular}

In addition to the diagnosed cases, seven meatcutters $(7.8 \%)$ showed some objective signs in the upper extremities, eg, local tenderness in the region of the epicondyli, in the physical examination.

All the meatcutters with epicondylitis had worked more than 15 years in their current occupation. The average length of the meatcutters' work life was 10 years.

Subjective symptoms. During the week before the subjects completed the questionnaire, $29 \%$ of the meatcutters and $7 \%$ of the referents had felt pain in the region of the epicondyli, whereas 43 and $16 \%$ of the meatcutters and referents, respectively, had felt pain in the same location during the last 12 months before the study. Thirty percent of the meatcutters and $10 \%$ of the referents had felt discomfort or pain in their wrists or hands during the week before the study. During the year preceding the study $54 \%$ of the meatcutters and $17 \%$ of the referents had felt pain in their wrists or hands.

All the reported symptoms were associated with increasing age, as well as with the dominant hand of the meatcutter. The results of the latex tests were negative. The sedimentation rates were within the normal range $(<10 \mathrm{~mm} / \mathrm{h})$.

\section{Discussion}

There is still controversy about the etiology and diagnostic criteria of epicondylitis and tenosynovitis $(5,9$, 10). Many authors agree that the external cause of epicondylitis is overexertion of the finger and wrist extensors (6). Grip and playing technique have been suspected to play some role as causative agents in the occurrence of tennis elbow $(9,10)$. It is possible that the etiology of the meatcutters' epicondylitis is associated with local muscle-tendon load. A meatcutter must, eg, overstrain the extensors and flexors of the wrist and fingers of his work hand, especially when he is cutting frozen meat. The individual work methods of meatcutters have to be taken into account also as a possible individual risk factor of epicondylitis.

Epicondylitis does not seem to be connected with repetitive or monotonous work movements so clearly as tenosynovitis, but the risk of epicondylitis is more associated with ageing than the risk of tenosynovitis $(4,5)$. Meatcutters do not use the small muscles of the hand and forearm in a repetitive monotonous way; instead they use the whole powerful musculature of the upper arm and shoulders in their work.

We chose relatively strict diagnostic criteria for our study in order to avoid false positive cases. Both authors detected almost the same number of cases (three and five). Therefore we believe that there was no significant observational bias.

In the normal male population of Finnish industry between the ages of 40 and 64 years the prevalence of pain and discomfort symptoms in the upper extremi- 
ties is about $9 \%$, and for the region of the hands and wrists the corresponding figure is $11 \%$ (11). For the same age group of the referents of the present investigation the corresponding prevalence was $10 \%$ in both cases. Although one must be cautious in comparing questionnaire data from different studies, the magnitude of discomfort symptoms seems to be clearly higher among meatcutters than among workers who are not exposed to repetitive movements of the upper extremities.

The use of self-administered questionnaires may cause some overreporting of subjective symptoms. However the fact that there were separate clinical symptoms in the clinical examination for almost $8 \%$ of the meatcutters who did not meet the criteria for epicondylitis favors the hypothesis that the meatcutters actually had more subjective symptoms of the upper extremities than the reference group.

In a recent report about the musculoskeletal complaints of meatcutters Hagberg et al (2) were able to show that local muscle strain increases the serum level of creatine kinase, a finding which indicates local overloading of muscles among meatcutters. Their observation about the localization and susceptibility factors of musculoskeletal complaints parallels our observations.

In another recent study about musculoskeletal disorders and complaints among workers in slaughterhouses, Wiikari-Juntura was not able to show epicondylitis among butchers and meat industry workers (13). The mean age of her study population was clearly lower than ours.

We are fully aware of the difficulties of interpreting cross-sectional data in favor of the hypothesis that meatcutting increases the risk of epicondylitis. However our observation that meatcutters with epicondylitis had been exposed, on the average, five years longer than the other meatcutters leads us to the conclusion that epicondylitis is probably associated with meatcutting. The overreporting of local musculoskeletal symptoms among meatcutters also supports the view that meatcutting causes local muscletendon load, which may cause epicondylitis in older meatcutters.

There seems to be a strong tendency towards early pensioning or change of work after the age about 50 years among slaughterhouse workers (3). If the same type of early retirement also occurs among meatcutters, our figures are probably underestimations. During the last seven years the Finnish unemployment rate has been $9-10 \%$. Therefore the opportunities for changing jobs have diminished dramatically since the early $70 \mathrm{~s}$. We think that this phenomenon has stabilized the study population, and selection due to discomfort symptoms is not a factor to be considered. More precise inferences on the association between meatcutting and epicondylitis would be possible in the context of an incidence type of study.

Our figures for tenosynovitis were low. Therefore it is not possible to make inferences about any association between meatcutting and tenosynovitis. The cases were more prevalent among the younger workers, and it is already generally known that tenosynovitis occurs more often in younger people (12).

\section{References}

1. Committee of the Nordic Council of Ministers. Project group report. Oslo 1982.

2. Hagberg M, Jonsson B, Brundin L, Ericson B-E, Örtelius A. Besvar frản rorelseorganen bland styckare: En epidemiologisk, ergonomisk och electromyografisk studie. Arbetarskyddsverket, Stockholm 1983, pp 37-38. (Arbete och hälsa 12).

3. Hansen N, Jeune B. Incidence of disability pensions among slaughterhouse workers in Denmark (with special regard to diagnosis of musculo-skeletal system) Scand j soc med (1982) 10: 81-85.

4. Kivi P. Käden ja kyynärvarren rasitusperäinen tenosynoviitti ja peritendiniitti. Duodecim 97 (1981) $729-736$.

5. Kivi P. The etiology and conservative treatment of numeral epicondylitis. Scand J Rehabil Med 15 (1982) $37-41$.

6. Kurppa K, Waris P, Rokkanen P. Tennis elbow: Lateral elbow pain syndrome. Scand J Work Environ Health 5 (1979): suppl 3, 15-18.

7. Mantel N, Haenszel W. Statistical aspects of the analysis of data from retrospective studies of disease. J Natl Cancer Inst 22 (1959) 719-748.

8. Miettinen OS. Estimability and estimation in casereferent studies. Am J Epidemiol 103 (1976) 226-235.

9. Nagler W. Tennis elbow. Am Fam Physician 16 (1977): 1, $95-102$.

10. Steiner C. Tennis elbow. J Am Osteopath Assoc.75 (1976) 575.

11. Takala J, Sievers K, Klaukka T. Rheumatic symptoms in the middle-aged population in southwestern Finland. Scand J Rheumatol (1982): suppl 47, 15-29.

12. Waris P. Occupational cervicobrachial syndromes. Scand J Work Environ Health 5 (1979): suppl 3, 3-14.

13. Wiikari-Juntura E. Neck and upper limb disorders among slaughterhouse workers. Scand J Work Environ Health 9 (1983) 283-290.

Received for publication: 27 February 1984 